\title{
Morphology of NmF2 nighttime increases in the Eurasian sector
}

\author{
A. V. Mikhailov ${ }^{1}$, T. Yu. Leschinskaya ${ }^{1}$, M. Förster ${ }^{2, *}$ \\ ${ }^{1}$ Institute of Terrestrial Magnetism, Ionosphere and Radio Wave Propagation, Troitsk, Moscow Region 142092, Russia \\ e-mail: avm71@orc.ru \\ ${ }^{2}$ GeoForschungsZentrum, Projektbereich 2.3, Telegrafenberg, D-14473 Potsdam, Germany
}

Received: 13 December 1999 / Revised: 3 March 2000 / Accepted: 7 March 2000

\begin{abstract}
A statistical analysis of two peaks (pre-midnight and post-midnight) occurrence in $\mathrm{NmF} 2$ daily variations was made on a latitudinal chain of four ionosonde stations in the Eurasian longitudinal sector. Overall 6182 cases of the first and 5600 cases of the second peak occurrence were analyzed using all available $f_{\mathrm{oF}} 2$ observations for the years of solar maximum and minimum. Well-pronounced and systematic variations with season and solar activity were revealed in the occurrence probability of the peaks, their amplitude and timing. The pattern of both peaks occurrence is similar during winter and equinoxes for midlatitude stations implying one and the same mechanism of their formation. The pre-midnight summer peak shows specific variations in particular during solar maximum pointing to a different mechanism controlling its appearance. Possible mechanisms of both peaks formation are discussed.
\end{abstract}

Key words: Ionosphere (electric fields and currents; ionosphere-magnetosphere interactions; mid-latitude ionosphere)

\section{Introduction}

Nocturnal electron density increase is a well-known mid- and lower-latitude F2-layer effect which is observed both in NmF2 and TEC (Arendt and Soicher, 1964; Evans, 1965, 1974; Da Rosa and Smith, 1967; Titheridge, 1968, 1973; Bertin and Papet-Lepine, 1970; Young et al., 1970; Tyagi 1974; Davies et al., 1979; Jakowski et al., 1986, 1991; Balan and Rao, 1987; Lois

\footnotetext{
Correspondence to: A. V. Mikhailov
}

* Present address: Max-Planck-Institut für extraterrestrische Physik, D-85740 Garching, Germany et al., 1990; Joshi and Iyer, 1990; Jakowski and Förster, 1995). Although TEC and NmF2 variations generally are close to each other, some differences in peak occurrence are stressed (Tyagi, 1974; Lois et al., 1990). Usually the first (pre-midnight peak mainly in summer) and the second (post-midnight, mainly during winter and equinoctial periods) peak in TEC and NmF2 daily variations are discussed and analyzed. Both maxima occurrence in the post-sunset F2-region are also mentioned (Balan and Rao, 1987; Lois et al., 1990; Jakowski et al., 1991;) and analyzed (e.g., Young et al., 1970; Rao et al., 1982; Joshi and Iyer, 1990). Unfortunately, the results of analysis are very controversial in various publications. Rao et al. (1982) made their analysis for some equatorial and mid-latitude stations in the Asian zone for solar maximum (1958) and solar minimum (1964) conditions. They found the amplitudes of both peaks to be larger at solar maximum while according to Tyagi (1974) and Titheridge (1973) the tendency is opposite. Different conclusions may be found on seasonal and solar cycle variations of the peaks timing. A statistical analysis of nighttime increases was made by Lois et al. (1990) and Jakowski et al. (1991) using observations over Havana-Cuba $(L=1.5)$ for the period of July 1974-December 1980. They confirmed the effect to be a regular feature of the winter season during solar minimum. It is most pronounced and longlasting around the December solstice. During solar maximum the nighttime increases become shorter in time, but their amplitude increases. This contradicts the results of Tyagi (1974) and Titheridge (1973), but agrees with Rao et al. (1982). An interesting result is that the seasonal pattern inverses during solar maximum and the occurrence probability of the effect maximizes in summer. This result contradicts other observations (e.g., Young et al., 1970). The amplitude of the effect strongly varies from night-to-night (e.g., Tyagi, 1974). Sometimes instead of an NmF2 increase a strong decrease may take place with a difference in $\mathrm{NmF} 2$ up to factor of 8 for two neighboring quiet time nights (Mikhailov and Förster, 1999). Such strong day-to-day variations are compara- 
ble with F2-layer storm effects during severe geomagnetic disturbances.

All previous morphological analyses of the effect were confined to particular stations or to a limited period of time. On one hand, as the nighttime $\mathrm{NmF} 2$ increases are related to plasmaspheric fluxes (Evans, 1965, 1975; Förster and Jakowski, 1988; Jakowski et al., 1991; Jakowski and Förster, 1995; Mikhailov and Förster, 1999) and depend on the tube content, the effect should manifest a latitudinal dependence (e.g., Balan and Rao, 1987; Feichter and Leitinger, 1987). On the other hand, there are contradictions between different observations of this effect concerning its seasonal and solar cycle variations. This may be due to either real longitudinal differences between the American (Lois et al., 1990; Jakowski et al., 1991) and the Asian (Rao et al., 1982) sectors or to the period analyzed, or may reflect differences in the method of analysis used. Further, usually the previous studies made no separations between quiet and disturbed periods. However, the nighttime peak formation is thought to be closely related to the thermospheric winds (Mikhailov and Förster, 1999) which are known to change during disturbed periods. Therefore, a more complete morphological study of this effect is required using available foF2 observations for 3-4 solar cycles using only quiet time periods. The analysis is made on a chain of ionosonde stations in the Eurasian longitudinal sector where the effect was not considered earlier. The results of such morphological study will be useful in further physical analysis of the effect in question.

\section{Method of data analysis}

All available hourly $f_{\mathrm{oF}} 2$ observations for four ionosonde stations: Alma-Ata $(43.25 \mathrm{~N} ; 76.92 \mathrm{E} ; L=1.52)$, Kiev (54.30E; 30.30E; $L=2.11$ ), Moscow (55.50N; $37.30 \mathrm{E} ; L=2.53)$, and St. Petersburg $(59.95 \mathrm{~N} ; 30.70 \mathrm{E}$; $L=3.18$ ) were analyzed for the years of solar maximum (1957-1959, 1968-1970, 1979-1981, 1989-1991) and solar minimum $(1964,1965,1975,1976,1985$, 1986). The selected years correspond to the periods around solar maxima and minima of the last four solar cycles. Alma-Ata has the same $L$-parameter as HavanaCuba analyzed by Lois et al. (1990) and Jakowski et al. (1991). This will allow us to compare the American and Eurasian longitudinal sectors.

The presence of any of two peaks was checked in NmF2 daily variations for the years in question. Figure 1 gives examples of such two peaks specification. The absolute minimum was searched in $\mathrm{NmF} 2$ values within the period after sunset to $02 \mathrm{LT}$, and this value was named $N_{\min }$. The amplitudes of both peaks, A1 and A2 equal to $N_{\text {peak }} / N_{\text {min }}$ and the local time of their occurrence were found for each case. These $L T$ moments were designated $T 1$ and $T 2$. A plateau of $2-3 \mathrm{NmF} 2$ hourly values was referred as a peak with its maximum in the middle of the plateau. Several maxima are possible after midnight. Therefore, the largest postmidnight maximum was found and it was treated as the
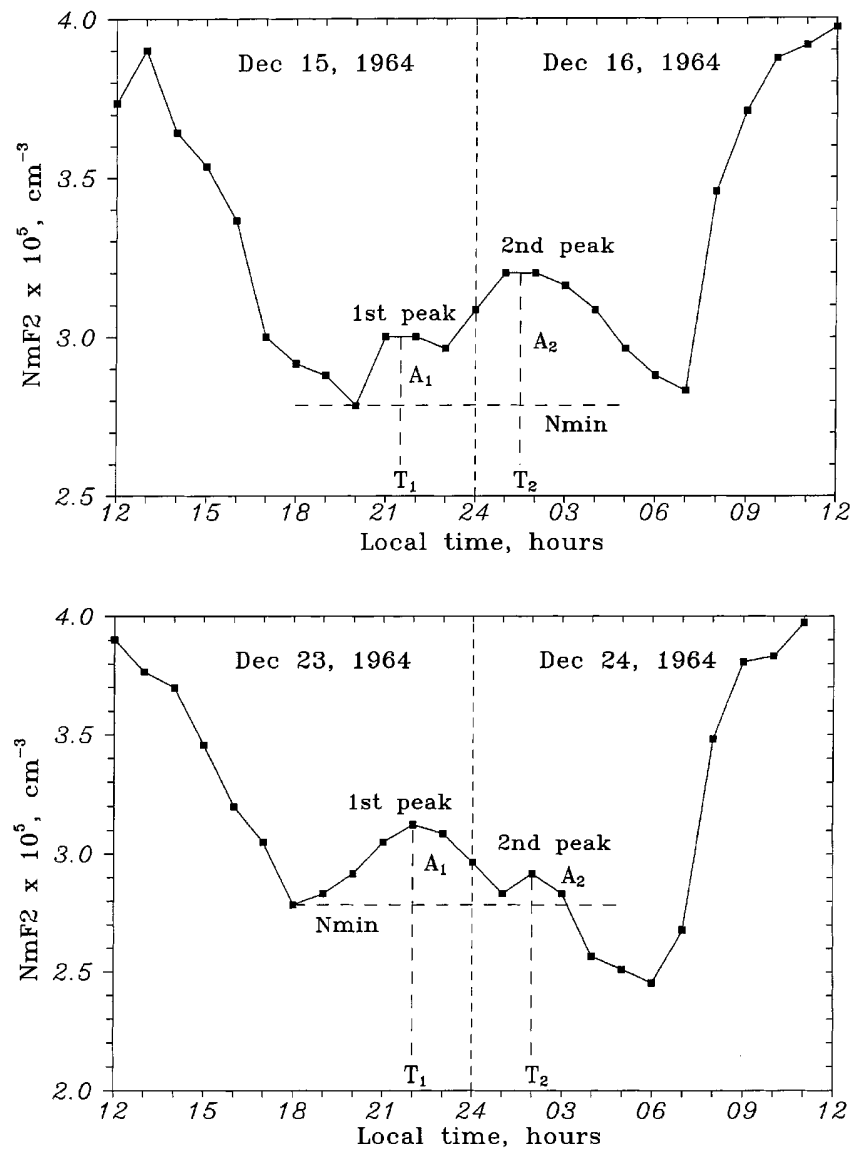

Fig. 1. Two peaks and $N_{\text {min }}, T, A$ parameter specifications in the $\mathrm{NmF} 2$ daily variations

second peak. One-hour gaps in observed $\mathrm{NmF} 2$ variations were filled in using neighboring observed values, days with two and more hourly gaps were omitted. To avoid the effects of solar illumination during summer nights only periods with solar zenith angle $>95^{\circ}$ at midnight were considered. Only quiet days with $A p \leq 12$ were analyzed to exclude storm effects, although nighttime $\mathrm{NmF} 2$ increases are frequent during storm periods. The results are presented both for 12 months of the year and in a combined form for three seasons: winter (November-February), summer (May-August), and equinox (March, April, September, October) for the periods of solar maximum and minimum.

\section{Results}

The total number of analyzed cases on each station is given in Table 1. Both peaks are seen to be observed about in half of all quiet days both at solar minimum and maximum, although the percentage of days with the nighttime increases is higher at solar minimum. An interesting result is that the occurrence of the first peak is higher than the second one at solar minimum. The occurrence probability of the two peaks is about the same during solar maximum. For the 1st peak one should keep in mind that in many cases it is not a 
Table 1. Total number of cases (upper) of all quiet days (bottom) considered

\begin{tabular}{lllll}
\hline Station & \multicolumn{2}{l}{ Solar minimum } & & \multicolumn{2}{l}{ Solar maximum } \\
\cline { 2 - 3 } & 1st peak & 2nd peak & 1st peak & 2nd peak \\
\hline Alma-Ata & $959 / 1438(67 \%)$ & $840 / 1438(58 \%)$ & $781 / 1812(43 \%)$ & $1056 / 1812(58 \%)$ \\
Kiev & $965 / 1460(66 \%)$ & $754 / 1460(52 \%)$ & $650 / 1493(43 \%)$ & $617 / 1493(41 \%)$ \\
Moscow & $767 / 1460(52 \%)$ & $695 / 1460(48 \%)$ & $926 / 1913(48 \%)$ & $803 / 1913(42 \%)$ \\
St.Petersburg & $386 / 1415(27 \%)$ & $227 / 1415(16 \%)$ & $748 / 1864(40 \%)$ & $609 / 1864(33 \%)$ \\
\hline
\end{tabular}

Table 2. Two peak occurrences in monthly median NmF2 variations solar minimum. Left-hand crosses, the 1st peak, right-hand crosses, the 2nd peak

\begin{tabular}{|c|c|c|c|c|c|c|c|c|c|c|c|c|}
\hline \multicolumn{13}{|c|}{ Alma-Ata (Solar minimum) } \\
\hline 1965 & + & + & & & & & & ++ & + & ++ & ++ & ++ \\
\hline 1975 & ++ & ++ & + & & & & & & + & ++ & ++ & ++ \\
\hline 1976 & ++ & ++ & + & & & + & & + & & ++ & ++ & ++ \\
\hline 1985 & ++ & ++ & ++ & & & & & + & + & + & ++ & ++ \\
\hline
\end{tabular}

Table 3. Same as Table 2 but for solar maximum

\begin{tabular}{|c|c|c|c|c|c|c|c|c|c|c|c|c|}
\hline \multicolumn{13}{|c|}{ Alma-Ata (Solar maximum) } \\
\hline 1959 & + & + & & & & + & + & & & + & ++ & ++ \\
\hline 1968 & ++ & + & & + & + & & + & & & & ++ & + \\
\hline 1969 & + & ++ & & + & + & & & + & & + & + & + \\
\hline 1970 & ++ & ++ & & & & & & & & + & + & + \\
\hline 1981 & + & ++ & & & & + & + & & + & + & ++ & ++ \\
\hline 1989 & + & ++ & & & & & + & & & & & + \\
\hline
\end{tabular}

pronounced peak such as shown in Fig. 1, but just a plateau before the main, 2nd peak. Table 1 gives the results averaged over all seasons, while there is a strong seasonal dependence in the peaks occurrence (see later).

In the beginning of the analysis it is necessary to stress that the $\mathrm{NmF} 2$ nighttime increase is a regular F2-layer feature manifested in the NmF2 monthly medians both at solar minimum and maximum. Tables 2 and 3 give as an example the annual occurrence of the two peaks in monthly NmF2 medians at the Alma-Ata station during solar maximum and minimum. Observed monthly medians were analyzed using the method mentioned to check the presence of both peaks in $\mathrm{NmF} 2$ diurnal variations and such cases are marked with crosses in Tables 2 and 3. Nighttime NmF2 increases are seen to be observed in monthly medians from October to March at solar minimum and from October to February at solar maximum. During these, mainly winter months, usually both maxima are present, while only one peak may be observed for the other months as a rule. Similar conclusions are obtained for Kiev and Moscow, but not for St. Petersburg where the distribution of nighttime peaks over the seasons does not show such a regularity especially at solar maximum. Unlike the three midlatitude stations, St. Petersburg is a sub-auroral station which is subjected to convection electric fields and particle precipitation effects during the nighttime, especially during high solar activity.

The results of the statistical analysis for the two peaks occurrence are given in Table 4 for four stations, three seasons, solar maximum and minimum conditions. Figures 2-5 give graphical presentation of the results for Alma-Ata and St. Petersburg. The results for Kiev and Moscow are similar to those for Alma-Ata on the whole and are not given to save printing space.

\subsection{The first peak (solar minimum)}

There is a well-pronounced seasonal dependence in the occurrence probability of the first peak (Figs. 2, 4, top graphs). For three midlatitude stations the maximum of occurrence is in winter (70-90\% of all quiet days) and minimum in summer $(30-50 \%)$. The seasonal variation is inverted for St. Petersburg, the nighttime increases are more frequent in summer (30-40\% of all quiet days) and 


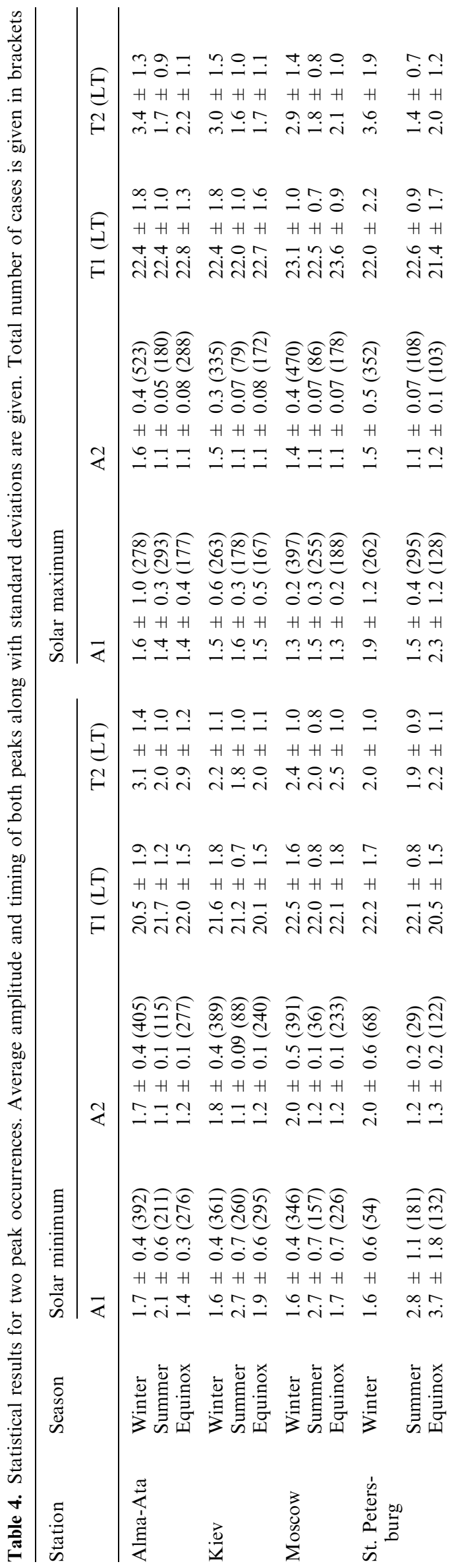

are rare in winter $(20-30 \%)$. The amplitude of summer increases is larger than winter ones for all stations, but the largest increases take place in St. Petersburg during equinoxes and this may be an indication of a relation with the equinoctial increase in geomagnetic activity. No systematic variation is seen in the timing of the peak which is observed at 20.5-22.5 LT.

\subsection{The first peak (solar maximum)}

Similar to solar minimum conditions the occurrence probability of the peak decreases from winter to summer months, but a sharp upsurge in the occurrence probability takes place in June-July (Figs. 2, 4) at all four stations (60-70\% of all quiet days). This is an interesting result not observed at solar minimum. There is also a pronounced tendency for the peak to appear later in the evening for all seasons (Table 4). The amplitudes of the peak on average are less for all seasons compared to solar minimum conditions (Table 4).

\subsection{The second peak (solar minimum)}

There is a well-pronounced seasonal dependence in the occurrence probability of the peak (Figs. 3, 5 and Table 4) at all four stations. For the three midlatitude stations the peak is most frequent in winter (NovemberFebruary, $80-90 \%$ of all quiet days) and is rare in summer (10-30\%) similar to results at Havana, Cuba, (Lois et al., 1990; Jakowski et al., 1991). At St. Petersburg the seasonal tendency is the same but the winter occurrence is low, $20-30 \%$ only. The amplitude of $\mathrm{NmF} 2$ increases also is the largest in winter at all four stations. A tendency for the amplitude to increase is seen when we pass from lower- to higher-latitude stations. There is also a systematic behavior in the timing of the peak appearance: it occurs later in winter and at equinox than in summer. These results agree with the conclusions obtained for Havana, Cuba at low solar activity.

\subsection{The second peak (solar maximum)}

At solar maximum there is the same seasonal dependence of the peak occurrence: the highest probability is in winter (75-85\% of all quiet days) and $10-30 \%$ in summer on the three midlatitude stations. A strong increase in the winter peak occurrence takes place at St. Petersburg (Fig. 5) compared to solar minimum conditions. The occurrence probability also increases for summer months at all stations considered, but the seasonal pattern keeps the same as at solar minimum. This contradicts the results by Lois et al. (1990) and Jakowski et al. (1991) at Havana, who found an inversion of the seasonal pattern with the highest peak occurrence in summer. It may be thought that there was a contaminating effect of the first peak which does have the highest occurrence in June-July at solar maximum (see earlier). In a similar way to solar minimum 

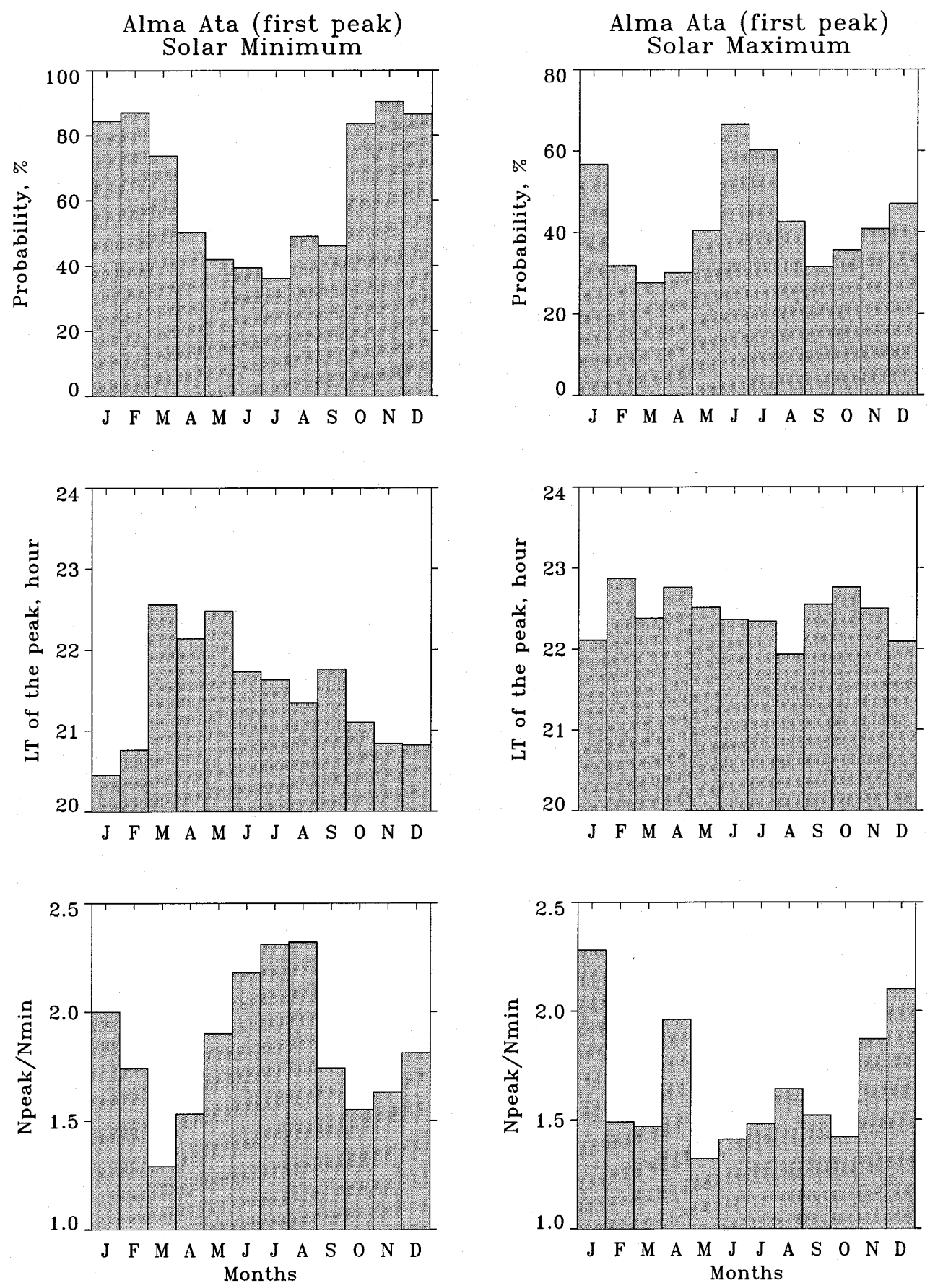

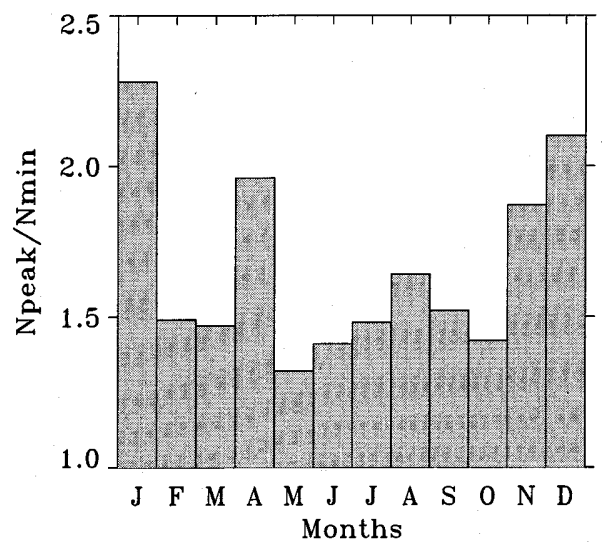

Fig. 2. Seasonal variations of occurrence probability (top), timing (middle), and amplitude (bottom) of the 1st peak at Alma-Ata at solar minimum (left-hand side) and solar maximum (right-hand side) conditions winter increases are the largest, but the amplitudes are lower compared to solar minimum (Figs. 3, 5 and Table 4).

Similar to solar minimum there is a clear seasonal dependence in timing of the peak: winter peaks are later than equinoctial and summer ones (Figs. 3, 5 and Table 4). Lois et al. (1990) and Jakowski et al. (1991) revealed no seasonal variations in the timing of the peak occurrence during solar minimum and showed the opposite to our results with a seasonal dependence during solar maximum with summer peaks to be the latest. Therefore, either there are longitudinal (American/Eurasian sectors) differences in the mechanism of the second peak formation at high solar activity, or these differences are related to different methods of analysis. An additional analysis on some American stations is required to confirm the longitudinal differences revealed.

\section{Simultaneous occurrence of the peaks}

It is interesting to check how often the peaks occur on one and the same days on different stations. This may help to specify the mechanism of their formation in various geophysical conditions. The results of such an 

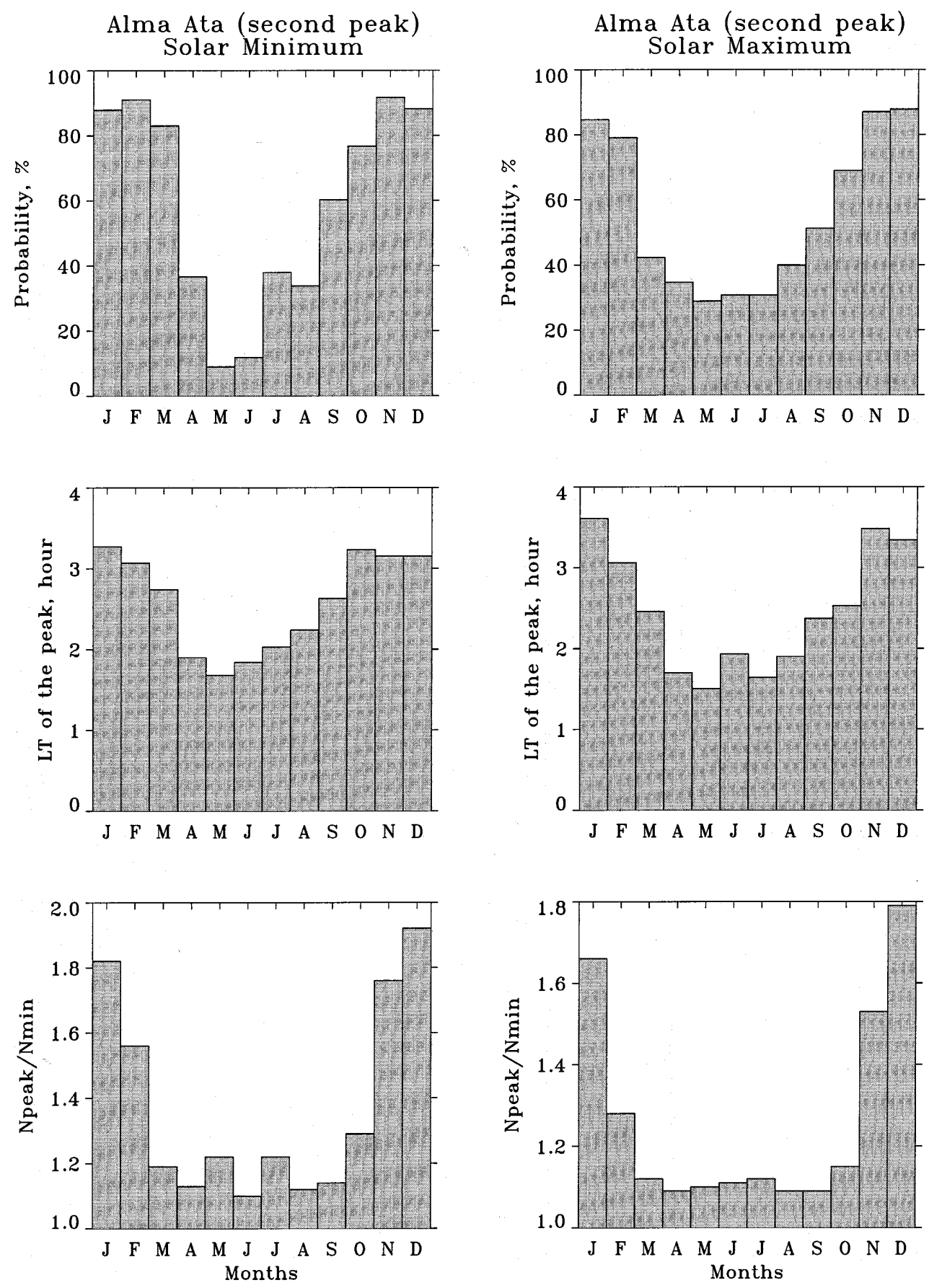

Fig. 3. Same as Fig. 2 but for the 2nd peak

analysis are given in Table 5. They are specified for the three midlatitude stations Alma-Ata, Kiev, Moscow (upper panel) and for all four stations (bottom panel). As St. Petersburg is a sub-auroral station with a somewhat different morphology of the peaks we consider the four-stations case separately.

Both peaks are very probably simultaneous at the three stations in winter (56 and $71 \%)$ at solar minimum. Of course, this may be due to a general high probability of the peaks occurring in these conditions (Figs. 2-5). However, the second peak, for instance, is also very often in winter at high solar activity at any of the three stations, nevertheless, it is observed simultaneously only on $47 \%$ of all days considered (Table 5). In general, the probability of simultaneous occurrence of peaks at the three stations is lower at high solar activity during winter and equinox, but is higher in summer compared to solar minimum conditions. This tells us that the stations are less coupled during high solar activity in winter and equinox if one and the same mechanism is presumed to be responsible for the peak formations at the chain of the stations considered. On the other hand, an increase of the stations coupling on the first peak in summer at solar maximum may indicate a different mechanism of this peak formation during summer time. 

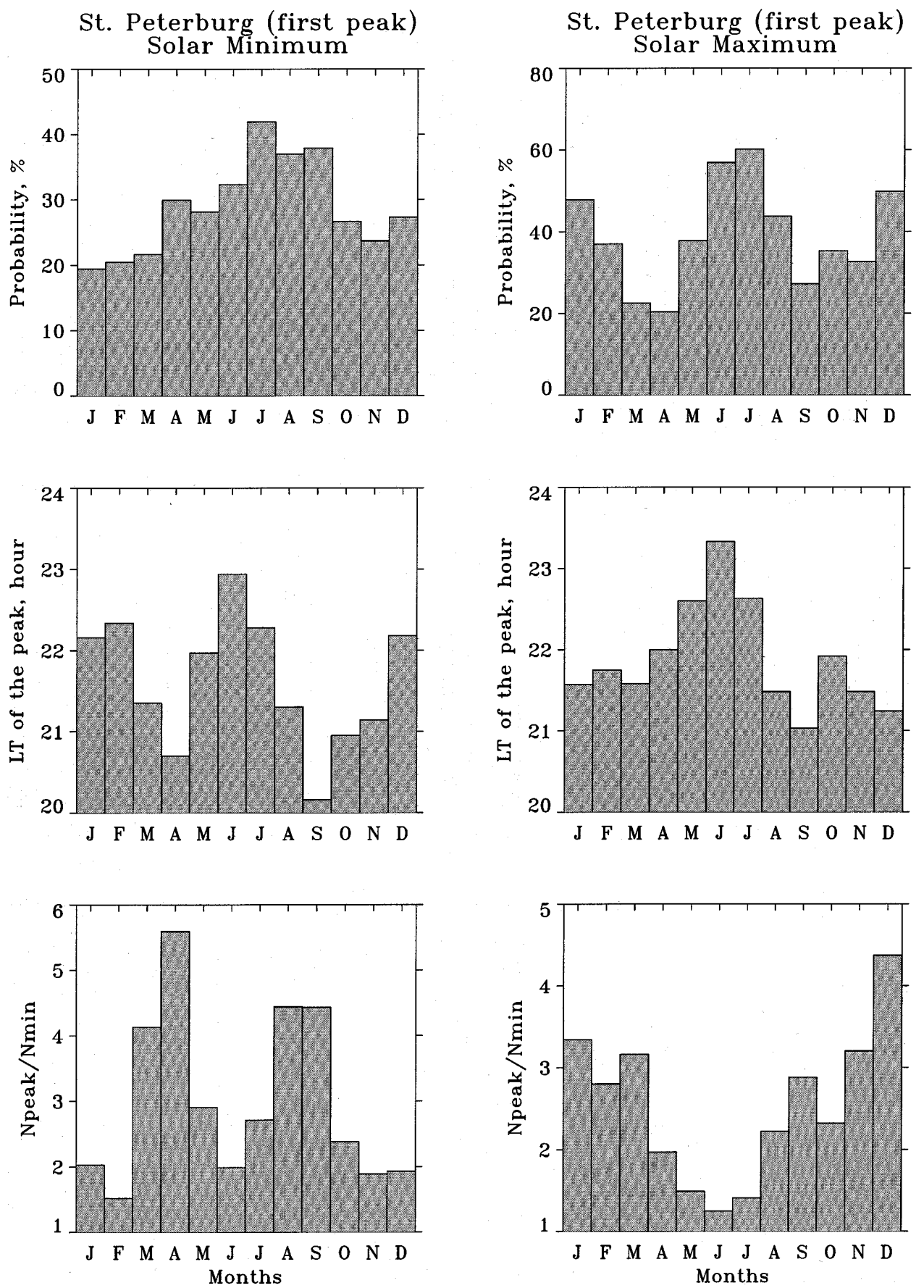

Fig. 4. Same as Fig. 2 but for St. Petersburg

The overall occurrence probability of the peaks simultaneously at four stations is much less compared to the three-stations case. Unlike the three midlatitude stations case the common probability is very low for both peaks $(10-14 \%)$ in winter at solar minimum (Table 5). Partly this is due to a general low occurrence probability of both peaks at St. Petersburg at solar minimum (Figs. 4,5 ). The only case when probability is high enough $(32 \%)$ is in winter at solar maximum when the second peak is very probable on all four stations. In general we may conclude that St. Petersburg as a subauroral station is not closely related to the midlatitude stations.
An interesting result is on the 1st peak occurrence in summer at solar maximum. The occurrence probability of this peak is rather high (about $60 \%$ ) for all four stations in June-July while the common occurrence probability is low $(10 \%)$. This confirms our conclusion about a different mechanism of this peak formation under summer conditions.

\section{Discussion}

The results of our analysis show well-pronounced and systematic seasonal and solar cycle variations in the 

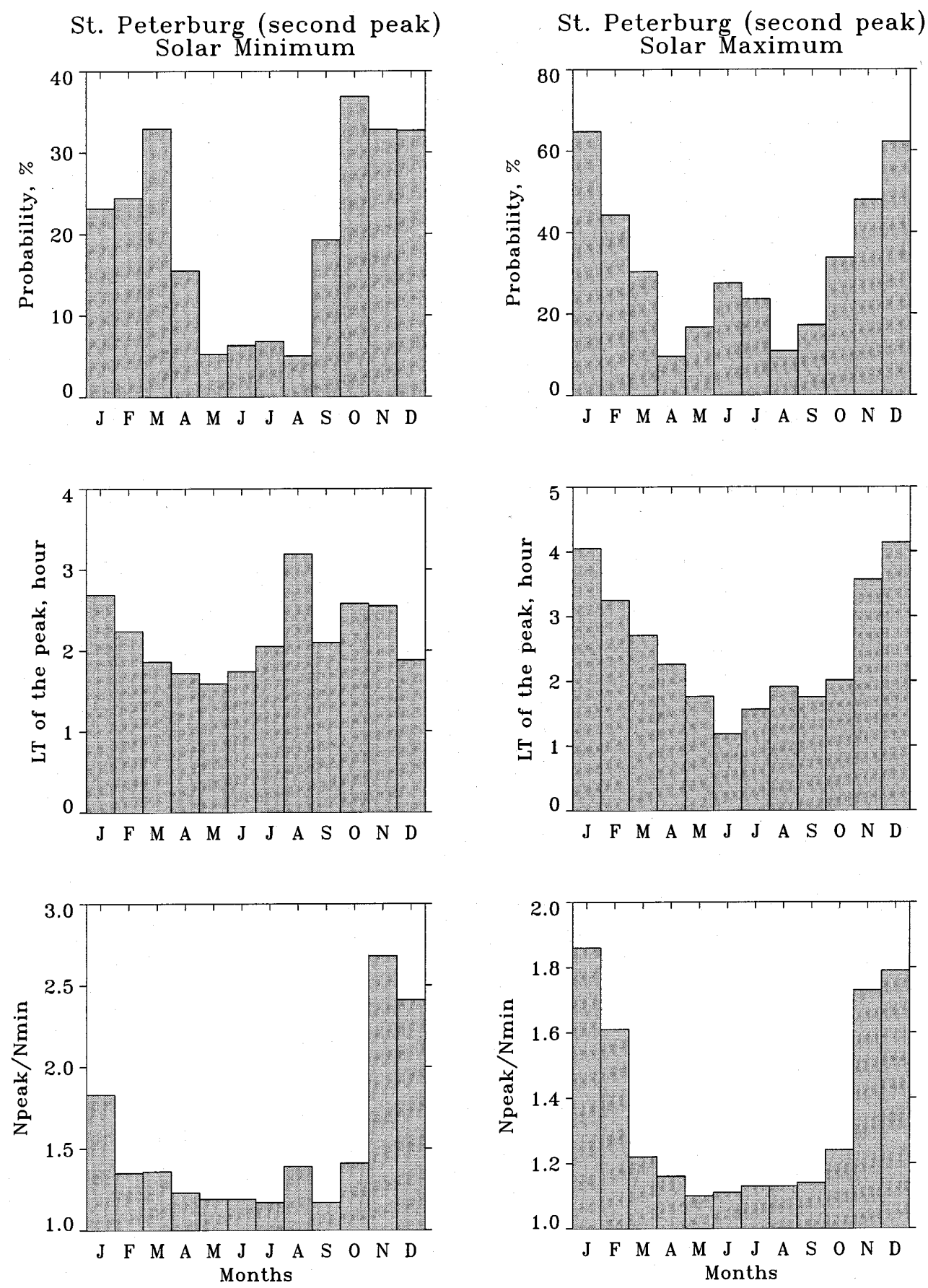

Fig. 5. Same as Fig. 4 but for the 2nd peak

Table 5. Total number of cases (upper) of all quiet days (bottom) with the peaks simultaneously observed at 3 and 4 stations

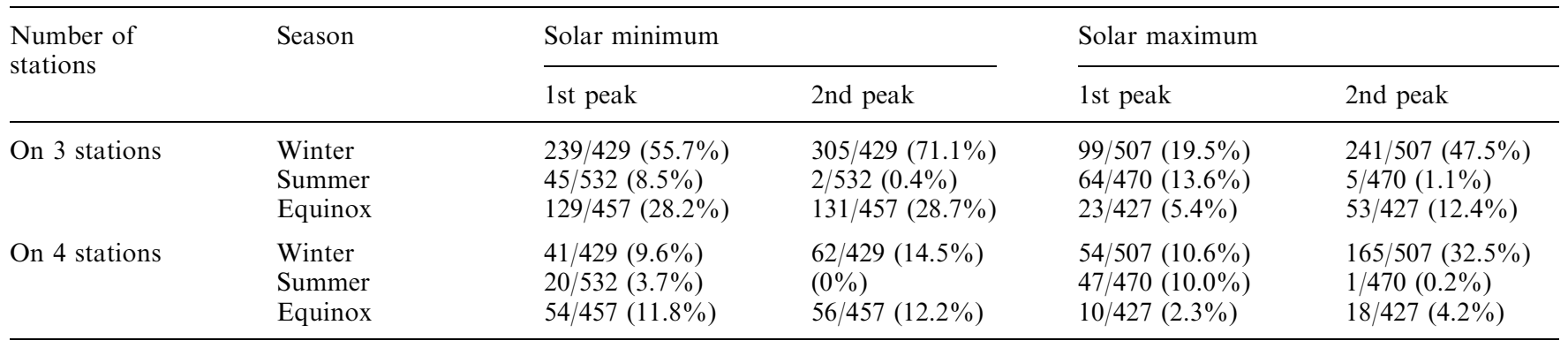


occurrence probability of the two peaks. On one hand, this indicates the ability of the method applied for such a kind of analysis. On the other hand, the systematic variations imply the existence of physical mechanisms responsible for such variations.

The first (pre-midnight) peak is well-observed at all four stations considered during the entire year both at high and low solar activity. However, the mechanism of its formation is thought to be different in various seasons. The largest amplitudes of the 1st peak are observed in summer at solar minimum at the three midlatitude stations. This evening NmF2 increase was discussed by Evans (1965) using Millstone Hill observations. Computer simulation studies (Sterling et al., 1969; Strobel and McElroy, 1970; Eccles and Burge, 1973) and subsequent observations (Evans, 1974) have shown that the summer evening $\mathrm{NmF} 2$ increase results from a collapse of the F2-layer that occurs when the electron temperature decreases at sunset. This produces large downward fluxes of the ions above hmF2. An additional contribution to the $\mathrm{NmF} 2$ increase is provided by the equatorward meridional thermospheric wind uplifting F2-layer into low rate recombination region during evening hours. This wind effect was shown to be more important (Eccles and Burge, 1973).

At high solar activity the amplitude of this summer evening NmF2 peak is reduced (see also Titheridge, 1973) compared to solar minimum (Figs. 2, 4), but the occurrence probability of the peak is very high in JuneJuly at all four stations. Although the solar zenith angle $\chi>95^{\circ}$ at 22-23 LT for all stations, this upsurge in the occurrence probability clearly indicates a relation with the Sun position. At high solar activity the neutral atmosphere scale height is large providing appreciable concentrations of neutral gases at high altitudes. Therefore, direct photoionization may be high enough in the topside even at large solar zenith angles. Model calculations are required to specify the mechanism of the 1st peak formation in summer at high solar activity. Another interesting result is the large equinoctial amplitudes of the 1st peak during solar minimum in St. Petersburg (Fig. 4). The timing of these peaks are seen to be the earliest in the whole year. No ideas on the mechanism of these peaks formation can be proposed at present.

The mechanism of the 1st peak formation in winter differs from the summer case. Although strong downward plasma fluxes also are observed around sunset (Evans, 1974) similar to summer time, it takes place two hours earlier in winter. By the time of sunset in summer (around $21 \mathrm{LT}$ ) a strong equatorward meridional wind (e.g., Evans and Holt, 1978; Wickwar, 1989; Buonsanto and Witasse, 1999) uplifts the F2-layer out of the region with fast recombination. Therefore, large downward plasma flux resulting from the topside electron temperature decrease is able to produce a pronounced evening NmF2 peak (see earlier). In winter by the time of sunset (around $18 \mathrm{LT}$ ) the meridional wind is still poleward or about to change the sign. The F2-layer is located at low heights where the recombination is fast. Therefore, additional plasma influx to the F2-region from above turns out to be inefficient. At the time when the F2-layer is being lifted by the vertical drift (due to the increasing equatorward wind) the recombination decreases and the plasmaspheric flux becomes efficient enough to produce the nighttime NmF2 increase. The amplitude of the $\mathrm{NmF} 2$ increase is controlled by the balance between plasma influx from the plasmasphere and total number of recombinations in the ionospheric column (IvanovKholodny and Mikhailov, 1986; Mikhailov and Förster, 1999).

Various observations give a nighttime electron density increase pattern with one (Evans, 1965, 1974; Tyagi, 1974) or two (Young et al., 1970; Balan and Rao, 1987; Rao et al., 1982; Jakowski et al., 1991) peaks. Occurrence of one or two peaks (before and after midnight) under the mechanism mentioned may be related to the prevailing thermospheric wind pattern in the region. Observations by Behnke and Harper (1973) at Arecibo show that the usual strong pre-midnight equatorward wind, maximizing around $22 \mathrm{LT}$, inverses around midnight. Downward drift increases the recombination producing a two-hump nighttime $\mathrm{NmF} 2$ peak. Computer simulation by Förster and Jakowski (1986, 1988) with a short reversal of the meridional wind around midnight similar to observations by Harper (1973) and Behnke and Harper (1973) confirmed the two peaks creation in $\mathrm{NmF} 2$ variation under this wind reversal mechanism. On the other hand, late occurrence of the 2nd peak during high solar activity cannot be explained by this method and additional analysis is required.

The second peak also demonstrates pronounced seasonal and solar activity variations in its occurrence probability, timing and the amplitude. The peak is wellpronounced in November-February with amplitudes of 1.5-2.0 (Figs. 3, 5; Table 4), but the amplitude is strongly reduced in other months. Qualitatively it is clear that the effect should be less pronounced in summer (Mikhailov and Förster, 1999), but additional quantitative analysis is required to understand the reasons for such sharp reduction of the amplitude during equinoctial and summer seasons. Another question concerns the seasonal variation of the peak timing (Fig. 3, Table 4). No explanation for this variation can be proposed now.

Simultaneous peak occurrences at the three midlatitude stations (Table 5) clearly indicates that the stations are closely related by a unique mechanism of both peak formations in winter and equinoxes, especially at low solar activity. The simultaneous action of the equatorward neutral wind and the plasmaspheric flow into the F2-region may play this role. It was shown earlier (Bertin and Papet-Lepine, 1970; Tyagi, 1974; Balan and Rao, 1987) that the occurrence probability of both peaks in TEC and $f \circ \mathrm{F} 2$ decreased rapidly towards the lower latitudes and vanishes practically at $\Phi>60^{\circ}$; the maximum probability takes place at $\Phi \approx 55^{\circ}$. The four stations considered are within these latitudinal limits. St. Petersburg with $\Phi=56^{\circ}$ should show good common occurrence probability for the peaks, but this is not the case (Table 5). Partly this may be related to many gaps 
in observations during nighttime hours, but may be due to longitudinal differences in this effect's occurrence.

\section{Conclusions}

The morphological study of the post-sunset $\mathrm{NmF} 2$ peaks occurrence on four ionosonde stations in the Eurasian sector has revealed the following.

1. There are two different peaks (pre-midnight and post-midnight) manifested in $\mathrm{NmF} 2$ local time variations during the whole year both at solar minimum and maximum.

2. The 1st peak is more frequent during solar minimum compared to solar maximum. There is a pronounced seasonal variation in the occurrence probability of the 1st peak, with the peak being more frequent in winter compared to summer time. This is valid for the midlatitude stations, but the pattern is opposite at the sub-auroral station St. Petersburg. Summer amplitude of the NmF2 increase is larger than winter one for the midlatitude stations. The largest amplitudes are observed at the sub-auroral station St. Petersburg during equinoxes.

3. During solar maximum the seasonal variation of the 1st peak occurrence probability is similar to the solar minimum pattern, but with a strong probability upsurge in June-July at all four stations. Generally the amplitude of the 1st peak is smaller compared to solar minimum conditions and the peak is shifted to later LT hours.

4. The 2nd peak shows a well-pronounced seasonal variation in the probability occurrence at the four stations, with the peak being more frequent in winter compared to summer, both at solar minimum and maximum. The largest amplitudes of the peak take place in winter, the amplitudes being small for other seasons. There is a tendency for the amplitude to increase with latitude. There is a pronounced seasonal variation in timing of the peak occurrence with winter peaks being later than summer ones.

5. Both peaks are very probable simultaneously at the three midlatitude stations in winter and equinox at solar minimum. This indicates a unique mechanism of both peaks formation in these seasons. The common occurrence probability of both peaks is less during winter and equinoxes at solar maximum compared to solar minimum conditions. This indicates that the stations are less coupled at solar maximum. An opposite behavior demonstrates that the 1 st peak in summer has an enhanced common occurrence probability. Together with the large increase of the peak occurrence in JuneJuly at solar maximum, this indicates a different mechanism of the 1st peak formation in summer at high solar activity.

6. The results of similar analysis at the four stations show that St. Petersburg, as a sub-auroral station, is not closely related to the midlatitude stations as the common occurrence probability of both peaks is rather low. While the occurrence probability of the 1 st peak is rather high (about 60\%) at all four stations in June-July at solar maximum, the common occurrence probability is low $(10 \%)$. This confirms the conclusion about a different mechanism of this peak formation under summer conditions.

Clearly these results of our morphological analysis revealed many interesting features of the nighttime $\mathrm{NmF} 2$ increases which need a theoretical interpretation.

Acknowledgements. This work was supported by the NATO Collaborative Research Grant EST.CLG 975303.

Topical Editor M. Lester thanks R. Leitinger and R. Hanbaba for their help in evaluating this paper.

\section{References}

Arendt, P. R., and H. Soicher, Downward electron flux at $1000 \mathrm{~km}$ altitude from electron content measurement at mid-latitudes, Nature, 204, 983-984, 1964.

Balan, N., and P. B. Rao, Latitudinal variations of nighttime enhancements in total electron content, J. Geophys. Res., 92, 3436-3440, 1987.

Behnke, R. A., and R. M. Harper, Vector measurements of F-region ion transport at Arecibo, J. Geophys. Res., 78, 8222-8234, 1973.

Bertin, F., and J. Papet-Lepine, Latitudinal variation of total electron content in the winter at middle latitude, Radio Sci., 5, 899-906, 1970.

Buonsanto, M. J., and O. G. Witasse, An updated climatology of thermospheric neutral winds and $\mathrm{F}$ region ion drifts above Millstone Hill, J. Geophys. Res., 104, 24,675-24,687, 1999.

Davies, K., D. N. Anderson, A. K. Paul, W. Degenhardt, G. K. Hartman, and R. Leitinger, Nighttime increase in total electron content observed with the ATS 6 radio beacon, J. Geophys. Res., 84, 1536-1542, 1979.

Da Rosa, A. V., and F. L. Smith, Behavior of the nighttime ionosphere, J. Geophys. Res., 72, 1829-1836, 1967.

Eccles, D., and J. D. Burge, The behavior of the upper ionosphere over North America at sunset, J. Atmos. Terr. Phys., 35, $1927-$ 1934, 1973.

Evans, J. V., Cause of midlatitude winter night increase in $f_{\mathrm{OF}}$, J. Geophys. Res., 70, 4331-4345, 1965.

Evans, J. V., Millstone Hill Thomson scatter results for 1965, Planet Space. Sci., 18, 1225-1253, 1970.

Evans, J. V., Millstone Hill Thomson scatter results for 1969, Lin. Lab., M.I.T. Tech. Rep. N 513, 1974.

Evans, J. V., A study of F2 region night-time vertical ionization fluxes at Millstone Hill, Planet. Space Sci., 23, 1611-1623, 1975.

Evans, J. V., and J. M. Holt, Millstone Hill Thomson scatter results for 1972, Lin. Lab., M.I.T. Tech. Rep. N 530, 1978.

Feicher, E., and R. Leitinger, Die Anwendung interaktiver statistischer Methoden auf den Electroneninhalt der Ionosphere, Kleinheubacher Beri, 30, 155-164, 1987.

Förster, M., and N. Jakowski, Interhemispheric ionospheric coupling at the American sector during low solar activity. II. Modelling, Gerlands Beitr. Geophys., Leipzig, 95, 301-314, 1986.

Förster, M., and N. Jakowski, The nighttime winter anomaly (NWA) effect in the American sector as a consequence of interhemispheric ionospheric coupling, PAGEOPH, 127, 447471, 1988

Harper, R. M., Nighttime meridional neutral winds near $350 \mathrm{~km}$ at low to mid-latitudes, J. Atmos. Terr. Phys., 35, 2023-2034, 1973.

Ivanov-Kholodny, G. S., and A. V. Mikhailov, The prediction of ionospheric conditions, D. Reidel, Dordrecht, The Netherlands, 1986.

Jakowski, N., and M. Förster, About the nature of the nighttime winter anomaly effect (NWA) in the F-region of the ionosphere, Planet. Space Sci., 43, 603-612, 1995. 
Jakowski, N., M. Förster, B.Lazo, and L. Lois, Interhemispheric ionospheric coupling at the American sector during low solar activity. I. Observations, Gerlands Beitr. Geophys., Leipzig, 95, 219-227, 1986.

Jakowski, N., A. Jungstand, L. Lois, and B. Lazo, Nighttime enhancement of the F2-layer ionization over Havana, Cuba, J. Atmos. Terr. Phys., 53, 1131-1138, 1991.

Joshi, H. P., and K. N. Iyer, On nighttime anomalous enhancement in ionospheric electron content at lower mid-latitude during solar maximum, Ann. Geophysicae, 8, 53-58, 1990.

Lois, L., H. Peres, B. Lazo, N. Jakowski, and R. Landrock, Nighttime enhancement of the F2-layer ionization over $\mathrm{Ha}$ vana-Cuba: a relationship with solar activity, Geomag. Aeronom., 30, 76-82, 1990.

Mikhailov, A. V., and M. Förster, Some F2-layer effects during the January 06-11, 1997 CEDAR storm period as observed with the Millstone Hill incoherent scatter facility, J. Atmos. Solar-Terr. Phys., 61, 249-261, 1999.

Rao, M. M., P. E. Raj, and C. Jogulu, A study of the post-sunset increase in the F2-region electron density at low- and middle latitudes in the Asian zone during sunspot maximum and minimum periods, Ann. Geophysicae, 38, 357-365, 1982.

Sterling, D. L., W. B. Hanson, R. J. Moffett, and R. G. Baxter, Influence of electromagnetic drifts and neutral air winds on some features of the F2 region, Radio Sci., 4, 1005-1023, 1969.

Strobel, D. F., and M. B. McElroy, The F2-layer at middle latitudes, Planet Space Sci., 18, 1181-1202, 1970.

Titheridge, J. E., Nighttime changes in the electron content of the ionosphere, J. Geophys. Res., 73, 2985-2993, 1968.

Titheridge, J. E., The electron content of the southern mid-latitude ionosphere, 1965-1971, J. Atmos. Terr. Phys., 35, 981-1001, 1973.

Tyagi, T. R., Electron content and its variation over Lindau, J. Atmos. Terr. Phys., 36, 475-487, 1974.

Wickwar, V. B., Global thermospheric studies of neutral dynamics using incoherent scatter radars, Adv. Space Res., 9, (5)87(5)102, 1989.

Young, D. M. L., P. C. Yuen, and T. H. Roelofs, Anomalous nighttime increases in total electron content, Planet Space Sci., 18, 1163-1179, 1970 